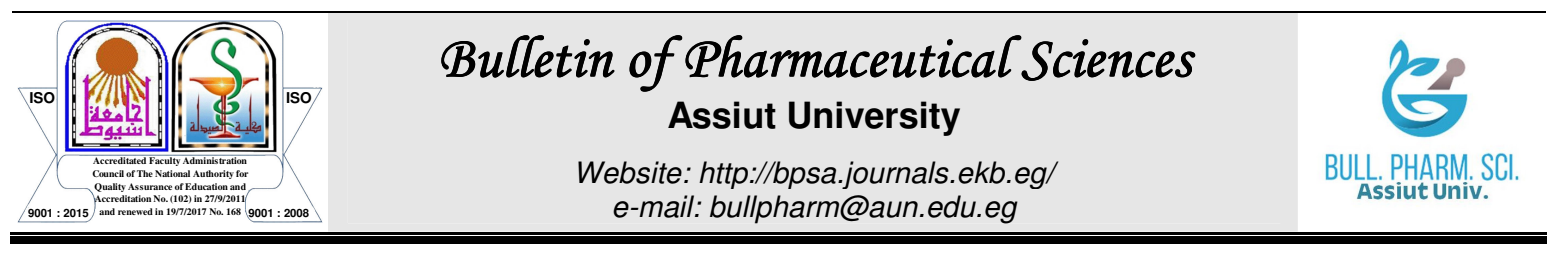

\title{
EFFECT OF ESSENTIAL OILS ON TRANSDERMAL PERMEATION OF METOPROLOL SUCCINATE
}

Kishorkumar Sorathia, Mehul Patel*, Tejal Soni, Vidur Vaghasiya, Jaydip Patel and B. N. Suhagia

Faculty of Pharmacy, Dharmsinh Desai University, Nadiad, Gujarat-387001, India

\begin{abstract}
The objective of the present study was to prepare a matrix-type transdermal drug delivery system containing metoprolol succinate and to evaluate the effect of essential oils on transdermal permeation of drug. The solvent evaporation method was employed to fabricate transdermal patches of drug using HPMC K15M and Acrycoat L100 as polymers and polyethylene glycol 400 as a plasticizer. Prepared patches were subjected for evaluation of physical as well as physicochemical properties, moisture characteristics, and ex-vivo drug permeation studies. The results of physical characterization showed uniform casting and good appearance of patches. Satisfactory mechanical strength was revealed in the results of tensile strength and folding endurance. Ex-vivo permeation study indicated enhancing effect of essential oils on drug permeation through the skin. The maximum flux observed was 94 $\mu \mathrm{g} / \mathrm{cm} 2 . \mathrm{hr}$ achieved by formulation M3 containing lemongrass oil (20\%). The results suggested that lemongrass oil was effective at higher concentration (20\%) after 14 hrs of permeation while peppermint oil and eucalyptus oil were effective at low concentration (10\%). Release kinetic suggested diffusion-controlled release of drug which followed the Korsmeyer-Peppas model. In conclusion, essential oils can be utilized as a safe and effective alternative for the permeation enhancement of drugs through transdermal delivery.
\end{abstract}

\section{INTRODUCTION}

Transdermal drug delivery has been paid attention as an alternative dosage form to oral delivery $^{1 \& 2}$. In addition to being appropriate for special populations who may have a problem with swallowing, transdermal delivery can avoid the first-pass metabolism and maintain constant plasma drug concentration. Despite these advantages, only a limited number of drugs can be administered percutaneously, due to the low permeability of most of the drugs through the skin.

The major obstacle in the successful development of the transdermal system is the barrier properties of skin which prevent penetration of drug and other substances. The stratum corneum (SC), an outer layer of skin, has been recognized as a potential barrier against skin penetration of most of the drugs ${ }^{3}$. To achieve and maintain a therapeutic concentration of drug in the blood, the resistance of skin (stratum corneum) to the diffusion of drugs must be reduced in order to allow drug molecules to cross the skin. To widen the applicability of transdermal systems, permeation enhancement is a prerequisite to overcome the barrier properties of the skin. Permeation enhancers are the compounds, which promote skin permeability by altering the skin barrier to the flux of the desired penetrant and are considered as an integral part of most transdermal formulations ${ }^{4}$. They can modify the skin's barrier to penetration either by interacting with the formulation that applied or with the skin itself ${ }^{5}$. Incorporation of chemical penetration enhancers into transdermal applications has been used since the sixties. Permeation enhancers must be pharmacologically inert, nonirritating, nontoxic, nonallergic, compatible with drugs and excipients, odourless, tasteless, colourless, 
and economical ${ }^{6}$. Some of the examples of the most widely studied penetration enhancers include sulphoxides, azone, pyrrolidones, urea, fatty acids and their derivatives (like lauric acid, myristic acid, caprylic acid, oleic acid), alcohols (ethanol, 2-propanol, caprylic alcohol), propylene glycol, glycerol, surfactants, chelating agents as well as essential oils and their constituents such as terpenes, terpenoids ${ }^{7}$.

Chemical permeation enhancers are able to partition into the stratum corneum and interact with its components to diminish the permeability barrier momentarily without causing significant damage to cells. The mechanism of permeation enhancement can be explained well by the lipid-protein partitioning theory $^{8 \& 9}$. The theory suggested a direct effect of enhancers on skin barrier through alteration in skin lipids or proteins or by modifying drug solubility or thermodynamic activity. Generally, enhancers combining high potency and safety are believed to act on the intercellular stratum corneum lipids because these lipids provide the major permeation pathway for most drugs ${ }^{10}$. The mechanism of action of enhancers can be related to solubility parameters, physicochemical interactions, and thermodynamic activity as suggested by recently introduced solubility-physicochemicalthermodynamic theory ${ }^{11}$.

Recently, considerable research is in progress on the use of essential oils derived from natural products as permeation enhancers to improve drug permeation due to their high permeation enhancement abilities and low irritancy potential ${ }^{12}$. Permeation enhancement by essential oils can be attributed to a mechanism through which they change the structure of the SC barrier and interact with intercellular SC lipids and thereby increase the diffusivity of drugs. Essential oils improve drug delivery via the skin by interacting with the intercellular lipids through different physical processes like increased disorder, phase separation, and fluidization. Essential oils and their volatile components can penetrate through the skin and act as penetration enhancer through various mechanisms mainly based on (i) disintegration of the highly ordered intercellular lipid structure between corneocytes in stratum corneum, (ii) interaction with the intercellular domain of proteins, which induces their conformational modification, (iii) increase the partitioning of a drug. They readily and rapidly metabolised after application and hence not accumulated in the tissue and excreted rapidly. So, essential oils and their constituents can be accepted as a natural alternative to chemical penetration enhancer ${ }^{12}$. Most investigations in this respect have focused on the fatty acid, terpenes from essential oils as permeation enhancers ${ }^{13-15}$.

Metoprolol succinate is used in the treatment of mild to moderate hypertension. It is almost completely absorbed after oral administration, although the systemic bioavailability varies widely owing to extensive presystemic metabolism (40-60\%). The plasma half-life is about four hours, which makes frequent dosing necessary to maintain the therapeutic blood levels of drugs ${ }^{16-18}$. Low bioavailability (about 20-30\%) due to extensive hepatic first-pass metabolism associated with the oral route can be avoided by transdermal administration. To overcome this, several studies have been reported by various researchers on controlled release matrix transdermal patches of metoprolol succinate with the use of DMSO as chemical permeation enhancer which can facilitate to minimize dose and help to improve the patient compliance. Metoprolol succinate is thus, a drug of choice for controlled release matrix-type transdermal drug delivery which provides several benefits including sustained release of drug, reduced dosing frequency, improved bioavailability, and ultimately improve patient compliance ${ }^{19 \& 20}$.

Aquil et $a l^{21}$ have formulated and evaluated matrix type transdermal patches of metoprolol tartrate using Eudragit RL100 and polyvinyl pyrrolidone K-30. They used 5\% $\mathrm{w} / \mathrm{w}$ dimethyl sulfoxide as permeation enhancer. In another study, they reported that menthol could be used as a permeation enhancer for metoprolol tartrate ${ }^{22}$.

The present work was aimed to study the effect of permeation enhancer on a matrixdispersion-type transdermal drug delivery system of metoprolol succinate. In this investigation, essential oils such as eucalyptus oil, peppermint oil and lemongrass oil were evaluated for their effect on drug permeation through the skin by ex-vivo skin permeation study. Prepared patches were also subjected for evaluation of physical as well as 
physicochemical properties including weight and thickness uniformity, tensile strength, folding endurance, content uniformity, as well as moisture content, moisture uptake, and water vapour permeation study.

\section{MATERIALS AND METHODS}

\section{Materials}

Metoprolol succinate was received as a gift sample from Troikaa Pharmaceuticals Ltd., Ahmedabad. Eucalyptus oil (Assay as Eucalyptol $>70.0 \%$; Sp. Gr. at $25^{\circ} \mathrm{C} 0.905$ to 0.925 ; RI at $20^{\circ} \mathrm{C} 1.458$ to 1.470 ), peppermint oil (Assay for total esters as Menthyl Acetate 5.0\%; Assay for total Menthol $>50.0 \%$; Sp. Gr. at $25^{\circ} \mathrm{C} 0.896$ to 0.908 ; RI at $20^{\circ} \mathrm{C} 1.459$ to 1.465 ) and lemongrass oil (Assay for aldehydes as Citral $>75.0 \%$; Sp. Gr. at $25^{\circ} \mathrm{C} 0.890$ to 0.904 ; RI at $25^{\circ} \mathrm{C} 1.483$ to 1.489 ) were purchased from SD Fine Chem Pvt. Ltd., Mumbai. Metolose (HPMC) and Acrycoat L100 were received as gift samples from ShinEtsu Chemical Co. Ltd., Japan, and Corel Pharma Chem, Ahmedabad respectively. Other materials and chemicals used in the study were of analytical grade.

\section{Preparation of transdermal patches}

The matrix patches of metoprolol succinate were prepared by the solvent evaporation technique ${ }^{19 \& 23}$. The weighed quantities (Table 1) of polymers were dissolved in $40 \mathrm{ml}$ solvent mixture containing dichloromethane and methanol in a ratio of 1:1. Plasticizers $(20 \% \mathrm{w} / \mathrm{w}$ of dry polymers) were incorporated into this solution. To this solution metoprolol succinate $(156 \mathrm{mg})$ and permeation enhancer were added and mixed thoroughly with the help of magnetic stirrer for $30 \mathrm{~min}$. This polymeric solution was then poured into a Petri dish (9 $\mathrm{cm}$ diameter) placed on a flat even surface. The rate of evaporation was controlled by inverting the funnel over the Petri dish. After drying at room temperature for $24 \mathrm{hrs}$, fabricated patches were collected, packed in aluminium foil and stored in desiccators containing silica gel as desiccant until further use. The composition of transdermal patches of metoprolol succinate is shown in table 1 .

\section{Physical characterization}

All the transdermal patches were inspected visually for colour, clarity, flexibility, and smoothness. To determine weight uniformity, patches from various batches were dried at $60^{\circ} \mathrm{C}$ for $4 \mathrm{hrs}$ before testing. Five patches from each batch were accurately weighed in a digital balance and average weights, as well as standard deviation values, were calculated from the individual weights $^{24}$.

The thicknesses of the drug-loaded polymeric patches were measured with the use of a screw gauge at five different points ${ }^{25}$. To measure the thickness, patches from each batch were placed between two glass slides of known thickness. The average and standard deviation of five readings were calculated for each batch of the drug-loaded patches.

\section{Tensile strength}

The tensile strength of patches was determined using a tensilometer. A patch of size $1 \mathrm{~cm}^{2}$ was held between two clamps and weight was gradually applied to increase the pulling force till the patch broke. The force required to break the patch was considered as tensile strength and it was calculated as $\mathrm{kg} / \mathrm{cm}^{2}{ }^{26}$.

$$
\begin{aligned}
& \text { Tensile Strength }\left(\mathrm{Kg} / \mathrm{cm}^{2}\right)= \\
& \frac{\text { Force to break film }(\mathrm{Kg})}{\text { Cross - sectional area of film }\left(\mathrm{cm}^{2}\right)}
\end{aligned}
$$

\section{Folding endurance}

Folding endurance was measured to determine the strength of the patch as well as the efficiency of the plasticizer. It was determined manually by repeatedly folding one patch at the same place till it broke $e^{27}$. The number of times the patch could be folded at the same place without breaking gave the value of folding endurance.

\section{Moisture content}

The patches were weighed individually and kept in a desiccator containing activated silica at room temperature. Individual patches were weighed repeatedly until they gained a constant weight. The percentage of moisture content was calculated as the difference between initial and final weight with respect to final weight ${ }^{28}$. 
Table 1: Formulation compositions for transdermal patches of metoprolol succinate.

\begin{tabular}{|c|c|c|c|c|c|c|}
\hline Batch $^{*}$ & $\begin{array}{c}\text { Metoprolol } \\
\text { succinate } \\
\text { (mg) }\end{array}$ & $\begin{array}{c}\text { HPMC } \\
(\mathrm{gm})\end{array}$ & $\begin{array}{c}\text { Acrycoat } \\
\text { L100 } \\
\text { (gm) }\end{array}$ & $\begin{array}{c}\text { Lemongrass } \\
\text { oil }\end{array}$ & $\begin{array}{c}\text { Peppermin } \\
\text { t oil }\end{array}$ & $\begin{array}{c}\text { Eucalyptus } \\
\text { oil }\end{array}$ \\
\hline M1 & 156 & 0.4 & 0.8 & -- & -- & -- \\
\hline M2 & 156 & 0.4 & 0.8 & $10 \%$ & -- & -- \\
\hline M3 & 156 & 0.4 & 0.8 & $20 \%$ & -- & -- \\
\hline M4 & 156 & 0.4 & 0.8 & -- & $10 \%$ & -- \\
\hline M5 & 156 & 0.4 & 0.8 & -- & $20 \%$ & -- \\
\hline M6 & 156 & 0.4 & 0.8 & -- & -- & $10 \%$ \\
\hline M7 & 156 & 0.4 & 0.8 & -- & -- & $20 \%$ \\
\hline
\end{tabular}

*All formulations contain polyethylene glycol (PEG 400) as plasticizer 20\% w/w of dry polymer.

\section{Moisture uptake studies}

Accurately weighed patches were kept in desiccators containing a saturated solution of potassium chloride (equivalent to $84 \%$ relative humidity) at room temperature for 3 days. The weights of patches were then measured again to determine moisture uptake. The percentage of moisture absorbed was calculated as the difference between final and initial weight with respect to the initial weight ${ }^{29}$.

\section{Water vapour transmission studies}

The glass vials of $5 \mathrm{ml}$ capacity were washed thoroughly and dried to constant weight in an oven. $1 \mathrm{~g}$ of fused calcium chloride was placed in vials and the polymer patches were fixed over the brim with the help of an adhesive. These pre-weighed vials were stored in the humidity chamber at $\mathrm{RH} 80 \%$ with a temperature of $25^{\circ} \mathrm{C}$ for a period of $24 \mathrm{hrs}$. The weight gain by vials were determined every hour for a period of $24 \mathrm{hrs}$ (predetermined equilibrium period). Water vapour transmission $^{28}$ was calculated by taking the difference in weight of vials before and after the study at a regular interval of $24 \mathrm{~h}$ for a total period of seven days.

\section{Content uniformity}

Content uniformity test was performed to determine the uniform distribution of drug throughout the formulation ${ }^{30}$. Three patches of $1 \mathrm{~cm}^{2}$ from each batch were dissolved separately in volumetric flasks containing $5 \mathrm{ml}$ methanol by stirring on a magnetic stirrer. The volume was adjusted to $100 \mathrm{ml}$ with phosphate buffer $\mathrm{pH} 7.4$ and the resultant solutions were filtered through Whatman filter paper. After suitable dilution with the same buffer, the absorbance of each solution was measured spectrophotometrically at $221.0 \mathrm{~nm}$ and drug content in each formulation was calculated using the calibration equation ${ }^{31}$.

\section{Ex-vivo skin permeation study}

Hairless animal skin is generally favoured as it is easily obtained from animals of a specific age group or sex. Goat skin was collected from the local slaughter house. Hairs on the skin of the goat were removed with an animal hair clipper, subcutaneous tissue was surgically removed and the dermis side was wiped with isopropyl alcohol to remove residual adhering fat. The skin was washed with distilled water. The skin so prepared was wrapped in aluminium foil and stored in a freezer at $-2^{\circ} \mathrm{C}$ till further use. The skin was defrosted at room temperature before use ${ }^{32}$.

Ex-vivo skin permeation ${ }^{33}$ was performed to predict drug release and performance invivo. Ex-vivo diffusion studies were performed by using a modified Franz diffusion cell with a receptor compartment capacity of $15 \mathrm{ml}$. The goat skin piece was mounted between two compartments of the diffusion cell with the epidermis facing upward into the donor compartment. The patch was placed on the skin surface and covered with aluminium foil. The receptor compartment of the diffusion cell was filled with phosphate buffer $\mathrm{pH} 7.4^{34}$. The whole assembly was fixed on a hot plate magnetic stirrer, and the solution in the receptor compartment was constantly and continuously stirred using magnetic beads and the temperature was maintained at $37 \pm 0.5^{\circ} \mathrm{C}$. The samples were withdrawn at predetermined 
time intervals and analyzed for drug content spectrophotometrically at $221.0 \mathrm{~nm}$. The receptor phase was replenished with an equal volume of fresh phosphate buffer after each sample withdrawal. The diffusion profile was constructed by plotting the amount of drug diffused against time.

\section{Diffusion parameters}

Ex-vivo drug permeation data were subjected to treatment with various kinetic equations to determine the mechanism of drug diffusion through the $\operatorname{skin}^{32}$. Permeation parameters like diffusion rate, flux, permeability coefficient, and enhancement ratio were also calculated from the permeation profile.

The diffusion rate is the amount of drug diffused through the membrane per unit time. It can be determined by dividing the amount of metoprolol succinate diffused by time $^{35}$. Permeation of drug through the skin is a passive diffusion process and can be described by Fick's second law which can be expressed mathematically as below.

$$
J_{s}=\frac{d Q}{d t} \times \frac{1}{A}
$$

Where $J_{S}$ is the steady-state flux in micrograms/square centimetre per hour, $d Q$ is the change in the quantity of material passing through the membrane into the receptor compartment expressed in micrograms, $A$ is the active diffusion area in square centimetres, and $d t$ is the change in time in hours.

The steady-state flux of the metoprolol succinate through the skin was calculated from the slope of the linear portion of the curve constructed by the cumulative amount of drug permeated through skin per unit area versus time $^{36}$. Permeability coefficient ${ }^{36}$ was calculated from values of flux using the following equation:

$$
K_{p}=\frac{J_{s}}{C_{d}}
$$

Where $K_{P}$ is the permeability coefficient, $J_{S}$ is the flux calculated at a steady time, and $C_{d}$ is the donor concentration.

Enhancement ratio ${ }^{37 \& 38}$ was used to evaluate the effect of permeation enhancer on diffusion and permeation of drug molecules through skin and calculated using the following equation.

$$
\begin{aligned}
& \text { Enhancement ratio }= \\
& \qquad \frac{K_{p} \text { of drug with permeation enhancer }}{K_{p} \text { of drug without permeation enhancer }}
\end{aligned}
$$

\section{Statistical analysis}

The values of the flux obtained for different formulations were tested for significant differences using a one-way ANOVA (Analysis of Variance) using a Dunnett's test as post hoc analysis. The statistical analysis was performed using Prism $^{\circledR} 5.0$ software (GraphPad Software, Inc., USA). Statistical significance was set at $p<$ 0.05 .

\section{RESULTS AND DISCUSSION}

All prepared transdermal patches were flat, transparent, and flexible with smooth surfaces. Patches prepared with lemongrass oil had yellowish-brown colour which can be attributed to the colour of lemongrass oil. Other patches were colourless. Physical and mechanical characteristics of transdermal patches i.e. weight variation, thickness, tensile strength, folding endurance are shown in table 2.

Weight and thickness of patches were found in the range of 0.024-0.028 gm and 0.47$0.57 \mathrm{~mm}$ respectively indicating no considerable variation in weight and thickness of patches. Smaller standard deviation values (Table 2) in patch weight and thickness measurements ensured the uniformity of weight and thickness in each patch. A good weight uniformity of all formulations indicated an even distribution of drug and polymers in the matrix patches prepared by the solvent evaporation technique. The results suggested no considerable effect of adding enhancers on weight and thickness of patches. Results also revealed the homogeneous casting of patches through uniform distribution of solution as well as consistent evaporation of solvent. As shown in table 2, all formulations have almost similar tensile strengths in the range of 3.51 to 3.65 $\mathrm{kg} / \mathrm{cm}^{2}$. Further, the addition of essential oils as permeation enhancers didn't alter the tensile strength of patches. 
Table 2: Physicochemical properties of transdermal patches of metoprolol succinate.

\begin{tabular}{|c|c|c|c|c|}
\hline Batch & $\begin{array}{c}\text { Weight of } \\
\text { Patch }^{*}(\mathrm{gm})\end{array}$ & $\begin{array}{c}\text { Thickness } \\
(\mathrm{mm})\end{array}$ & $\begin{array}{c}\text { Tensile } \\
\text { Strength }^{*} \\
\left(\mathrm{~kg} / \mathrm{cm}^{2}\right)\end{array}$ & $\begin{array}{c}\text { Folding } \\
\text { Endurance }^{\#}\end{array}$ \\
\hline M1 & $0.024 \pm 0.001$ & $0.47 \pm 0.00$ & $3.53 \pm 0.03$ & $12.3 \pm 1.53$ \\
\hline M2 & $0.028 \pm 0.002$ & $0.53 \pm 0.06$ & $3.51 \pm 0.03$ & $13.3 \pm 2.52$ \\
\hline M3 & $0.026 \pm 0.000$ & $0.50 \pm 0.10$ & $3.53 \pm 0.02$ & $15.7 \pm 1.53$ \\
\hline M4 & $0.024 \pm 0.000$ & $0.57 \pm 0.06$ & $3.62 \pm 0.02$ & $39.7 \pm 2.52$ \\
\hline M5 & $0.028 \pm 0.006$ & $0.53 \pm 0.06$ & $3.65 \pm 0.02$ & $38.3 \pm 2.52$ \\
\hline M6 & $0.026 \pm 0.001$ & $0.47 \pm 0.06$ & $3.51 \pm 0.03$ & $15.3 \pm 1.53$ \\
\hline M7 & $0.026 \pm 0.001$ & $0.53 \pm 0.00$ & $3.57 \pm 0.03$ & $17.7 \pm 0.58$ \\
\hline
\end{tabular}

*Results are mean \pm SD of $n=5$ observations.

"Results are mean \pm SD of $n=3$ observations.

Table 3: Moisture properties of transdermal patches.

\begin{tabular}{|c|c|c|c||}
\hline Batch & $\begin{array}{c}\text { Moisture } \\
\text { Content }^{*}(\%)\end{array}$ & $\begin{array}{c}\text { Moisture } \\
\left.\text { Uptake }^{*} \%\right)\end{array}$ & $\begin{array}{c}\text { Water Vapour } \\
\text { Transmission Rate } \\
\left(\mathrm{gm} / \mathrm{cm}^{2} . \mathrm{hr}\right)\end{array}$ \\
\hline M1 & $5.88 \pm 0.11$ & $15.63 \pm 0.19$ & $1.03 \times 10^{-3}$ \\
\hline M2 & $7.55 \pm 0.15$ & $13.33 \pm 0.12$ & $0.96 \times 10^{-3}$ \\
\hline M3 & $8.16 \pm 0.12$ & $11.36 \pm 0.14$ & $0.74 \times 10^{-3}$ \\
\hline M4 & $7.32 \pm 0.10$ & $11.63 \pm 0.09$ & $1.03 \times 10^{-3}$ \\
\hline M5 & $6.38 \pm 0.09$ & $12.50 \pm 0.15$ & $1.07 \times 10^{-3}$ \\
\hline M6 & $8.51 \pm 0.16$ & $16.33 \pm 0.18$ & $1.07 \times 10^{-3}$ \\
\hline M7 & $8.00 \pm 0.20$ & $13.73 \pm 0.17$ & $0.92 \times 10^{-3}$ \\
\hline
\end{tabular}

*Mean \pm SD of three determination has been reported.

As shown in table 2, formulation M4 and M5 had higher folding endurance (38-40) whereas all other formulations had folding endurance almost in the range of 12 to 17 . Formulation M4 and M5 contain peppermint oil which may also impart elasticity and act as a plasticizer. So this formulation showed higher folding endurance.

Results of moisture content, moisture uptake, and water vapour transmission rate are depicted in table 3 . The percent moisture content of patches was found in the range of $5.88 \pm 0.11$ to $8.51 \pm 0.16$. The results revealed no considerable changes in moisture content. Percent moisture uptake was found in the range of $11.36 \pm 0.14$ to $16.33 \pm 0.18$. Water vapour transmission rate of all formulation was also found invariable. No notable variations in moisture properties of formulations were observed as all formulations have the same polymer composition. These can also be attributed to similar concentration of plasticizer in all formulations.

Drug content was found in the range of 98.69 to $99.64 \%$ indicating good uniformity in the drug content within and between the batches. Results of drug content analysis of prepared patches revealed that the process employed to prepare patches in this study was capable of casting patches with uniform drug content and minimum batch variability.

In this study, matrix-type TDDS (transdermal drug delivery system) of metoprolol succinate was prepared using composite polymers with permeation enhancers. All formulations prepared were subjected to ex-vivo permeation study to evaluate the effect of permeation enhancer and their concentration. Drug permeation profiles of all formulations are shown in figure 1. It 


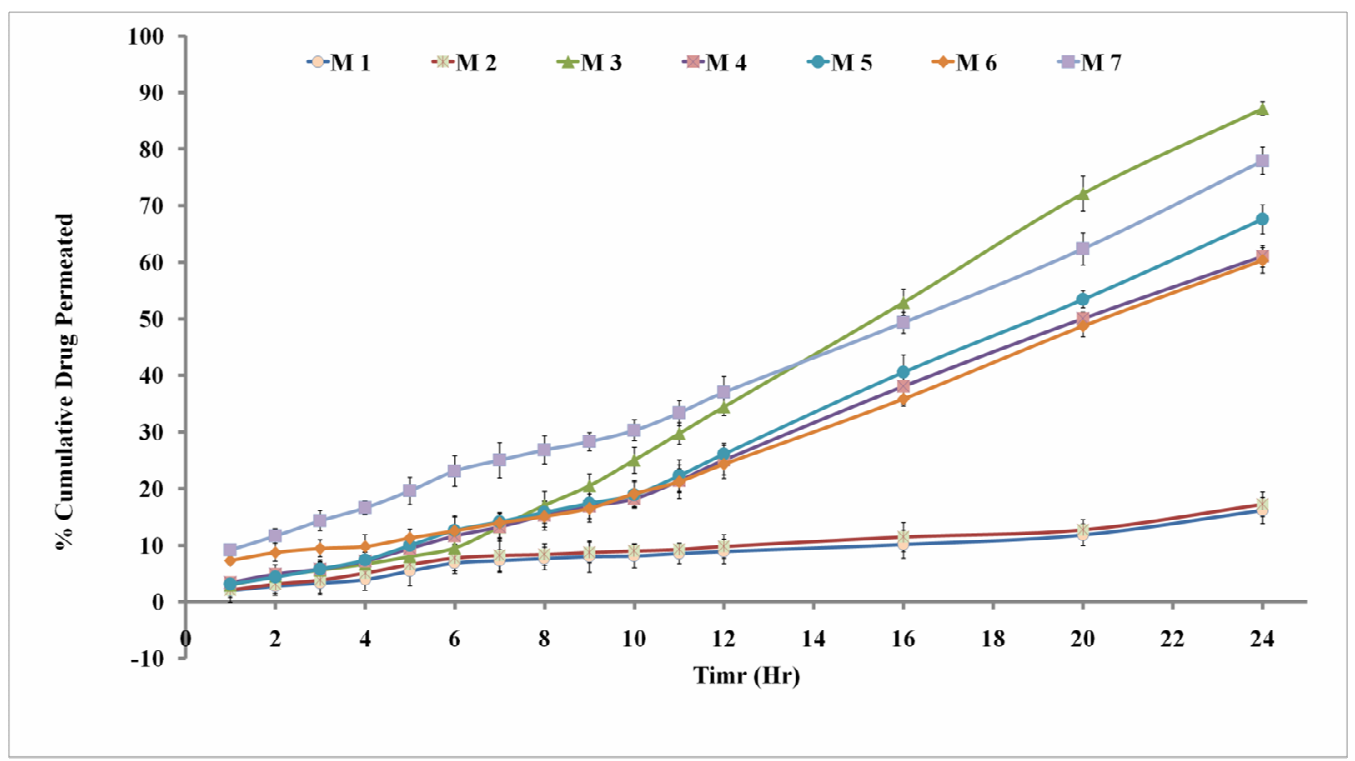

Fig. 1: Diffusion profiles of metoprolol succinate through goat skin.

shows that formulation $\mathrm{M} 7$ showed maximum drug permeation till $14 \mathrm{hrs}$ while M3 gave the highest drug permeation from 16 to $24 \mathrm{hrs}$, followed by M7. It is observed that there are three stages of times for drug permeation through goat skin:

Stage 1: from 0 to $7 \mathrm{hrs}$; the order of enhancement by oils from formulation can be given as: M7 > M6 > M5 > M4 > M3 > M2 > M1

Stage 2: from 8 to $14 \mathrm{hrs}$; the order of enhancement by oils from formulation can be given as: M7 > M3 > M5 = M4 > M6 > M2 > M1

Stage 3: from 16 to $24 \mathrm{hrs}$; the order of enhancement by oils from formulation can be given as: M3 > M7 > M $5>$ M4 > M6 > M2 > M1

All other formulations showed higher rates of drug permeation compared to M1 which does not contain any permeation enhancer. These findings suggested that essential oils like lemongrass oil, peppermint oil, and eucalyptus oil can be used as a permeation enhancer for metoprolol succinate.

\section{Effect of lemongrass oil}

Lemongrass oil was used in two concentrations in the present study. It was noticed that lemongrass oil at low concentration had not significantly $(p=0.06$, $>0.05$ ) increased drug permeation whereas at higher concentration (20\%), significantly ( $p<$ 0.05 ) increased the drug permeation after $8 \mathrm{hrs}$ as shown in figure 1 . As shown in table 4 , flux values attained for M2 and M3 were 14.33 $\mu \mathrm{g} / \mathrm{cm}^{2} . \mathrm{hr}$ and $94.21 \mu \mathrm{g} / \mathrm{cm}^{2} . \mathrm{hr}$ respectively. Permeability coefficient found for M3 was $1.70 \times 10^{-2} \mathrm{~cm} / \mathrm{hr}$ which is higher than M2 and M1. It was also observed that lemongrass oil at higher concentration gave maximum drug permeation compared to other used essential oils. Table 4 shows that enhancement ratio of M3 was 7.23 which is the highest of all other formulations. The results indicated that lemongrass oil was least effective as permeation enhancer at low concentration $(10 \%)$ while was the most effective at higher concentration (20\%). Lemongrass oil is an essential oil that usually contains terpenes and terpenoids, mainly citral. Skin permeation enhancement of metoprolol succinate can be attributed to terpenes present in lemongrass oil. Same findings were also reported by Prakash $e t$ $a l .{ }^{39}$ where terpenes present in lemongrass oil increased permeation of etoricoxib from a topical gel. Pathan et $a l .{ }^{40}$ have also reported that the permeation enhancement effect of terpene containing essential oils is primarily due to altered skin diffusivity mainly by disrupting lipid network. 
Table 4: Permeation parameters of transdermal patches.

\begin{tabular}{||c|c|c|c|c||}
\hline Batch & $\begin{array}{c}\text { Diffusion } \\
\text { Rate }(\mathrm{mg} / \mathrm{hr})\end{array}$ & $\begin{array}{c}\text { Steady state } \\
\text { Flux }\left(\mu \mathrm{g} / \mathrm{cm}^{2} . \mathrm{hr}\right)\end{array}$ & $\begin{array}{c}\text { Permeability } \\
\text { Coefficient } \\
(\mathrm{cm} / \mathrm{hr})\end{array}$ & $\begin{array}{c}\text { Enhancement } \\
\text { Ratio }\end{array}$ \\
\hline M1 & 0.039 & 13.00 & $0.24 \times 10^{-2}$ & 1.00 \\
\hline M2 & 0.043 & 14.33 & $0.25 \times 10^{-2}$ & 1.08 \\
\hline M3 & 0.175 & 94.21 & $1.70 \times 10^{-2}$ & 7.23 \\
\hline M4 & 0.125 & 62.14 & $1.12 \times 10^{-2}$ & 4.77 \\
\hline M5 & 0.134 & 68.47 & $1.23 \times 10^{-2}$ & 5.23 \\
\hline M6 & 0.123 & 56.56 & $1.01 \times 10^{-2}$ & 4.31 \\
\hline M7 & 0.174 & 70.35 & $1.27 \times 10^{-2}$ & 5.38 \\
\hline
\end{tabular}

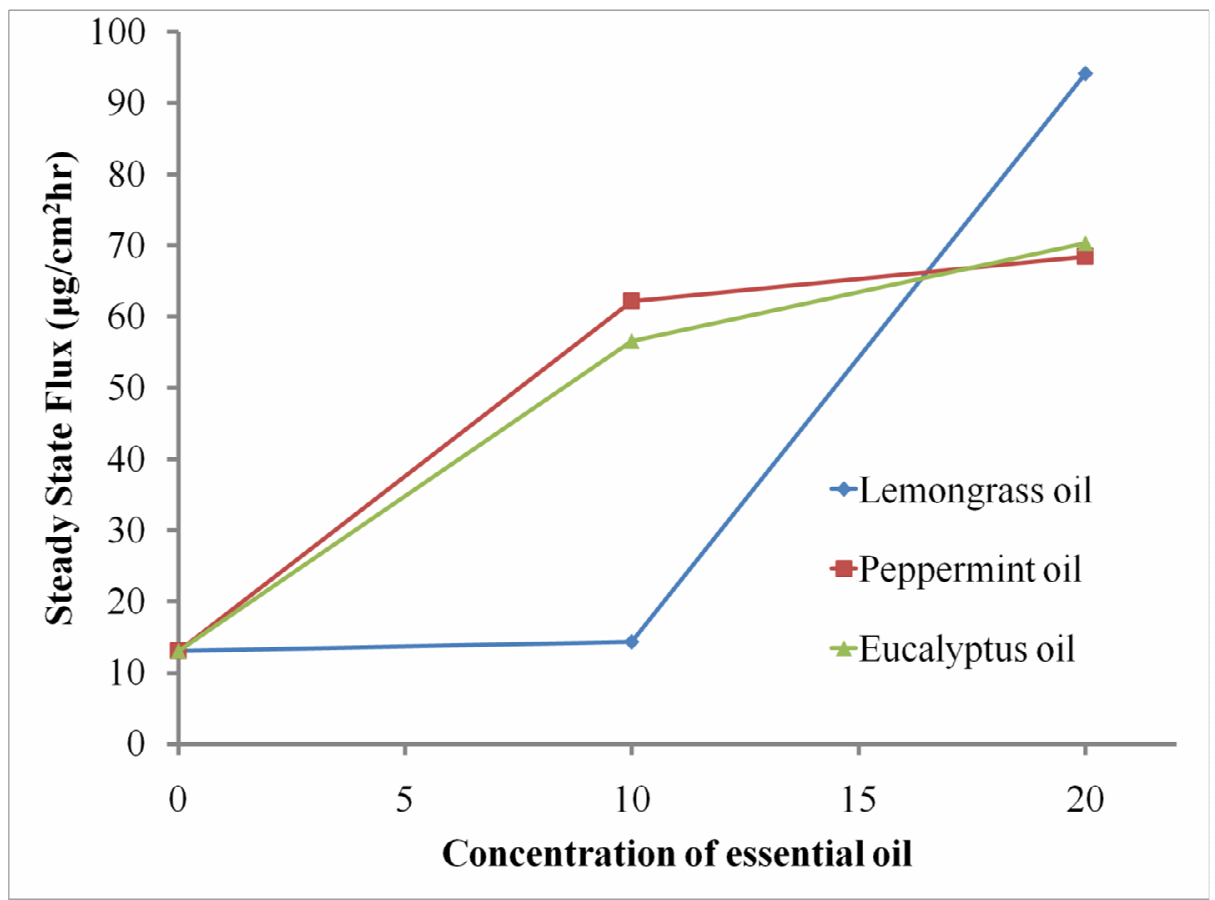

Fig. 2: Effect of essential oils and their concentrations on flux of metoprolol succinate through goat skin.

\section{Effect of peppermint oil}

From the results of permeation parameters shown in table 4 , it has been found that peppermint oil was efficient to enhance permeation at low concentration $(10 \%)$ and a further increase in concentration $(20 \%)$ had resulted in little increase in drug permeation. Flux values (Table 4) attained for formulation M4 and M5 were $62.14 \mu \mathrm{g} / \mathrm{cm}^{2} . \mathrm{hr}$ and 68.47 $\mu \mathrm{g} / \mathrm{cm}^{2}$.hr respectively while enhancement ratio of M4 and M5 were 4.77 and 5.23 respectively which showed no considerable difference. However, values for permeation parameters were found extensively greater compared to formulation M1 which indicated that peppermint oil has ability to enhance drug permeation significantly $(p<0.05)$ at low concentration of about $10 \%$. Findings were in good agreement with those reported by Kunta et $a{ }^{41}{ }^{41}$ where the permeation of propranolol hydrochloride across hairless mouse skin was significantly improved from patches containing menthol. This observation might be due to the preferential distribution of menthol into the intercellular spaces of $\mathrm{SC}$, which resulted in reversible disruption of $\mathrm{SC}$ lipid domains. 
Terpenes, mainly menthol, present in peppermint oil has been responsible for skin permeation enhancement of metoprolol succinate. It has been also reported that menthol affects skin permeation by a dual mechanism: by forming a eutectic mixture with the penetrating compound, thereby increasing its solubility; and by altering the barrier properties of the stratum corneum ${ }^{42 \& 43}$. Study performed by Kaplun-Frischoff and Touitou ${ }^{44}$ showed that menthol increased skin absorption of testosterone by forming a eutectic mixture, thereby lowering its melting point drastically which resulted in increase in the solubility of testosterone accompanied with altered barrier properties of SC.

\section{Effect of eucalyptus oil}

Flux values (Table 4) attained for formulation M6 and M7 were $56.56 \mu \mathrm{g} / \mathrm{cm}^{2} . \mathrm{hr}$ and $70.35 \mu \mathrm{g} / \mathrm{cm}^{2} . \mathrm{hr}$ respectively while enhancement ratio of M6 and M7 were 4.31 and 5.38 respectively which showed little difference. However, values for permeation parameters were found significantly $(p<0.05)$ greater compared to formulation M1 which indicated that eucalyptus oil has ability to enhance drug permeation at low concentration of about $10 \%$. As revealed in table 4 , the average diffusion rate of formulations M6 and M7 was found $0.123 \mathrm{mg} / \mathrm{hr}$ and $0.174 \mathrm{mg} / \mathrm{hr}$ respectively. As revealed by permeation parameters shown in table 4 and figure 2, the effect of eucalyptus oil on permeation was found almost similar to that of peppermint oil. Formulation M7 showed maximum drug permeation till $14 \mathrm{hrs}$ (Fig. 1) indicating enhanced drug permeation in presence of Eucalyptus oil. Eucalyptus oil is a major of source of eucalyptol (1,8-cineole), which was responsible for penetration enhancement of metoprolol succinate. The possible mechanism of enhancement of drug permeation was by disrupting intercellular lipid bilayers. It was reported that eucalyptol (1,8-cineole) increased the flux of indomethacin (lipophilic) and urea (hydrophilic) to a greater extent through fullthickness rat $\operatorname{skin}^{45}$. Xiong et al. ${ }^{46}$ had reported that high concentration ( $10 \%$ eucalyptol) is required to increase the permeation of low molecular weight heparin-enoxaparin sodium across human skin.

Lemongrass oil was found effective as permeation enhancer at higher concentration only after $14 \mathrm{hrs}$ as shown in figure 1 , and a significant effect $(p<0.05)$ of concentration of oil was observed. Peppermint oil and eucalyptus oil were also effective at a lower concentration as well as a little enhancement in permeation was found by increasing their concentration. Thus, essential oils like lemongrass oil, peppermint oil, and eucalyptus oil can drastically increase permeation of metoprolol succinate through the skin and can be utilized as a permeation enhancer ${ }^{47-49}$. Moreover, other essential oils have also been successfully utilized as safe and effective permeation enhancers for transdermal delivery of hydrophilic as well as lipophilic drugs. Godwin and Michniak $^{50}$ reported that the combination of terpenes with propylene glycol (PG) can significantly increase the transdermal penetration of the hydrophilic drug caffeine and the polar steroid hydrocortisone. Similar findings were also reported by Setty et al. ${ }^{51}$ where lemongrass oil (citral), mentha oil (menthol), and eucalyptus oil (cineole) were found effective in enhancing the skin permeation alone as well as in combination with propylene glycol.

Results of release kinetic analysis are reported in table 5 . It can be concluded from these results that Korsmeyer and Peppas model fitted the best for all the patches as correlation coefficient values for all the batches were more than $0.85^{52}$. This is followed by the zero-order equation and Higuchi. Formulation M1 and M2 followed the Higuchi model while formulation M3 to M7 followed zero-order kinetics. Amongst all, formulation M4 and M7 best fitted in zero order. From the $n$ value, it can be seen that all the formulations follow an anomalous pattern of drug release except M3, M4, and M5. This can be supported by the good fit of the Higuchi equation ${ }^{52}$. The drug was released by a diffusion-controlled mechanism from the polymeric matrix of patches. 
Table 5: Kinetics parameters of permeation profile of transdermal patches.

\begin{tabular}{||c|c|c|c|c|c|c|c|}
\hline \multirow{2}{*}{ Batch } & \multicolumn{2}{|c|}{ Zero Order } & \multicolumn{2}{c|}{ Higuchi } & \multicolumn{3}{c|}{ Korsmeyer Peppas } \\
\cline { 2 - 8 } & $\mathrm{K}_{0}$ & $\mathrm{R}^{2}$ & $\mathrm{~K}_{\mathrm{H}}$ & $\mathrm{R}^{2}$ & $\mathrm{~K}_{\mathrm{m}}$ & $\mathrm{R}^{2}$ & $\mathrm{n}$ \\
\hline M1 & 0.039 & 0.848 & 0.147 & 0.934 & 0.018 & 0.974 & 0.656 \\
\hline M2 & 0.043 & 0.803 & 0.162 & 0.951 & 0.021 & 0.978 & 0.641 \\
\hline M3 & 0.174 & 0.928 & 0.590 & 0.634 & 0.017 & 0.941 & 1.158 \\
\hline M4 & 0.127 & 0.967 & 0.441 & 0.705 & 0.023 & 0.957 & 0.949 \\
\hline M5 & 0.136 & 0.957 & 0.471 & 0.686 & 0.022 & 0.966 & 1.004 \\
\hline M6 & 0.126 & 0.957 & 0.444 & 0.730 & 0.047 & 0.849 & 0.671 \\
\hline M7 & 0.177 & 0.975 & 0.640 & 0.847 & 0.071 & 0.959 & 0.675 \\
\hline
\end{tabular}

\section{Conclusion}

Results of the study indicated that essential oils like lemongrass oil, peppermint oil, and eucalyptus oil could be used as transdermal penetration enhancers for metoprolol succinate. Patches of all batches had desired physical, physicochemical, and moisture properties. From the results of the exvivo skin permeation study, it was found that all three studied essential oils enhanced the drug permeation. Maximum drug permeation was found for the formulation containing $20 \%$ lemongrass oil followed by $20 \%$ eucalyptus oil. The results also suggested that lemongrass oil was effective at higher concentration (20\%) while peppermint oil and eucalyptus oil were effective at low concentrations (10\%). Release kinetic suggested diffusion-controlled release of drug which followed the Korsmeyer-Peppas model. It was concluded that the matrix transdermal drug delivery system of metoprolol succinate using essential oils as permeation enhancers could be a better alternative to conventional delivery systems.

\section{Acknowledgement}

Authors are thankful to Troikaa Pharmaceuticals Ltd., Ahmedabad for providing gift sample of Metoprolol succinate. Authors are also thankful to Shin-Etsu Chemical Co. Ltd., Japan and Corel Pharma Chem, Ahmedabad for providing Metolose (HPMC) and Acrycoat L100 as gift samples.

\section{REFERENCES}

1- A. Nokhodchi, J. Shokri, A. Dashbolaghi, D. Hassan-Zadeh, T. Ghafourian and M. Barzegar-Jalali, "The enhancement effect of surfactants on the penetration of lorazepam through rat skin", Int. J. Pharm., 250, 359-369 (2003).

2- H. S. Gwak, S. U. Kim and I. K. Chun, "Effect of vehicles and enhancers on the in-vitro permeation of melatonin through hairless mouse skin", Arch. Pharmacal Res., 25, 392-396 (2002).

3- G. K. Menon and A. M. Kligman, "Barrier functions of human skin: A holistic view", Skin Pharmacol. Phys., 22, 178-189 (2009).

4- H. S. Gwak and I. K. Chun, "Effect of vehicles and penetration enhancers on the in-vitro percutaneous absorption of tenoxicam through hairless mouse skin", Int. J. Pharm., 236, 57-64 (2002).

5- V. R. Sinha, S. Bindra, R. Kumria and A. Nanda, "Cyclodextrins as skin-penetration enhancers", Pharm. Technol., 27, 120138 (2003).

6- S. S. Jagannath, S. D. Manohar and R. B. Bhanudas, "Chemical penetration enhances - A review", World J. Pharm. Pharm. Sci., 3, 1068-1680 (2014).

7- H. J. Patel, D. G. Trivedi, A. K. Bhandari and D. A. Shah, "Penetration enhancers for transdermal drug delivery system: A review", IJPI's J. Pharm. Cosmetol., 1, 67-80 (2011).

8- B. Barry, "Lipid-protein-partitioning theory of skin penetration enhancement", J. Control. Release, 15, 237-248 (1991).

9- B. W. Barry, "Mode of action of penetration enhancers in human skin", $\boldsymbol{J}$. Control. Release, 6, 85-97 (1987).

10- A. C. Williams and B. W. Barry, "Penetration enhancers", Adv. Drug Deliv. Rev., 56, 603-618 (2004). 
11- A. Haq, M. Chandler and B. MichniakKohn, "Solubility-physicochemicalthermodynamic theory of penetration enhancer mechanism of action", Int. J. Pharm., 575, 118920 (2020).

12- A. Herman and A. P. Herman, "Essential oils and their constituents as skin penetration enhancer for transdermal drug delivery: A review", J. Pharm. Pharmacol., 67, 473-485 (2015).

13- Y. B. Huang, J. Y. Fang, C. H. Hung, P. C. $\mathrm{Wu}$ and $\mathrm{Y}$. H. Tsai, "Cyclic monoterpene extract from cardamom oil as a skin permeation enhancer for indomethacin: Invitro and in-vivo studies", Biol. Pharm. Bull., 22, 642-646 (1999).

14- D. Monti, P. Chetoni, S. Burgalassi, M. Najarro, M. F. Saettone and E. Boldrini, "Effect of different terpene-containing essential oils on permeation of estradiol through hairless mouse skin", Int. J. Pharm., 237, 209-214 (2002).

15- J. Y. Fang, Y. L. Leu, T. L. Hwang and H. C. Cheng, "Essential oils from sweet basil (Ocimum basilicum) as novel enhancers to accelerate transdermal drug delivery", Biol. Pharm. Bull., 27, 1819-1825 (2004).

16- V. G. Jamakandi, B. Ghosh, B. G. Desai and J. Khanam, "Recent trends in transdermal cardiovascular therapy", Ind. J. Pharm. Sci., 68, 556-561 (2006).

17- C. G. Regårdh and G. Johnsson, "Clinical pharmacokinetics of metoprolol", Clin. Pharmacokinet., 5, 557-569 (1980).

18- S. C. Sweetman, P. S. Blake, J. M. McGlashan and C. G. Martindale, "Martindale: The Complete Drug Reference", London: Pharmaceutical Press, 2005, p-234.

19- D. M. K. Chakradhar, A. Sunitha, B. Sofia and G. Srikar, "Design and development of transdermal drug delivery systems of metoprolol succinate", Int. J. Pharm. Chem. Anal., 6, 76-84 (2019).

20- P. Koteswararao, S. Duraivel, K. P. Sampath Kumar and B. Debjit, "Formulation and evaluation of transdermal patches of anti-hypertensive drug metoprolol succinate", Ind. J. Res. Pharm. Biotech., 1, 629-634 (2013).

21- M. Aqil, Y. Sultana and A. Ali, "Matrix type transdermal drug delivery systems of metoprolol tartrate: In-vitro characterization", Acta Pharmaceut., 53, 119-125 (2003).

22- M. Aqil, Y. Sultana, A. Ali, K. Dubey, A. K. Najmi and K. K. Pillai, "Transdermal drug delivery systems of a beta blocker: Design, in-vitro, and in-vivo characterization", Drug Deliv., 11, 27-31 (2004).

23- A. B. Nair, S. Jacob, B. E. Al-Dhubiab and R. N. Alhumam, "Influence of skin permeation enhancers on the transdermal delivery of palonosetron: An in-vitro evaluation", J. Appl. Biomed., 16, 192197 (2018).

24- V. G. Jamakandi, J. S. Mulla, B. L. Vinay and H. N. Shivakumar, "Formulation, characterization, and evaluation of matrixtype transdermal patches of a model antihypertensive drug", Asian J. Pharm., 3, 59-65 (2009).

25- N. A. El-Gendy, N. A. Sabry, M. El-Attar, E. Omar and M. Mahmoud, "Transdermal delivery of salbutamol sulphate: Formulation and evaluation", Pharm. Dev. Technol., 14, 216-225 (2009).

26- R. Gannu, V. Vishnu, V. Kishan and Y. M. Rao, "Development of nitrendipine transdermal patches: In-vitro and ex-vivo characterization", Curr. Drug Del., 4, 6976 (2007).

27- V. K. Devi, S. Saisivam, G. R. Maria and P. U. Deepti, "Design and evaluation of matrix diffusion controlled transdermal patches of verapamil hydrochloride", Drug Dev. Ind. Pharm., 29, 495-503 (2003).

28- R. Gupta and B. Mukherjee, "Development and in-vitro evaluation of diltiazem hydrochloride transdermal patches based on povidone-ethylcellulose matrices", Drug Dev. Ind. Pharm., 29, 1-7 (2003).

29- U. Ubaidulla, M. V. S. Reddy, K. Ruckmani, F. J. Ahmad and R. K. Khar, "Transdermal therapeutic system of carvedilol: Effect of hydrophilic and hydrophobic matrix on in-vitro and in-vivo characteristics", AAPS PharmSciTech., 8, 13-20 (2007).

30- P. N. Kotiyan and P. R. Vavia, "Eudragits: Role as crystallization inhibitors in drugin-adhesive transdermal systems of 
estradiol", Eur. J. Pharm. Biopharm., 52, 173-180 (2001).

31- N. Verma, A. K. Ghosh and P. Chattopadhyay, "UV-spectrophotometric determination of metoprolol succinate", Res. J. Pharm. Tech., 4, 271-272 (2011).

32- A. K. Jain, N. S. Thomas and R. Panchagnula, "Transdermal drug delivery of imipramine hydrochloride: I. Effect of terpenes", J. Control. Rel., 79, 93-101 (2002).

33- G. K. Jain, A. K. Sharma and S. S. Agrawal, "Transdermal controlled administration of verapamil-enhancement of skin permeability", Int. J. Pharm., 130, 169-177 (1996).

34- M. Shabbir, S. Ali, M. Farooq, S. Adnan, M. Yousaf, A. Idrees, K. Rehman and N. Shahid, "Formulation factors affecting invitro and ex-vivo permeation of bisoprolol fumarate from a matrix transdermal patch", Adv. Poly. Tech., 35, 237-247 (2016).

35- G. S. Sanap, G. Y. Dama, A. S. Hande, S. P. Karpe, S. V. Nalawad, R. S. Kakade and U. Y. Jadhav, "Preparation of transdermal monolithic systems of indapamide by solvent casting method and the use of vegetable oils as permeation enhancer", Int. J. Green Pharm., 2, 129 (2008).

36- G. C. Ceschel, P. Maffei and M. Gentile, "Design and evaluation of a new transdermal formulation containing chlorpheniramine maleate", Drug Dev. Ind. Pharm., 25, 1035-1039 (1999).

37- R. Sadashivaiah, B. M. Dinesh, U. A. Patil, B. G. Desai and K. S. Raghu, "Design and in-vitro evaluation of haloperidol lactate transdermal patches containing ethyl cellulose-povidone as film formers", Asian J. Pharm., 2, 43-49 (2008).

38- A. Melero, T. M. Garrigues, P. Almudever and A. M. I. Villodre, "Nortriptyline hydrochloride skin absorption: Development of a transdermal patch", Eur. J. Pharm. Biopharm., 69, 588-596 (2008).

39- P. R. Prakash, N. G. R. Rao and C. Soujanya, "Formulation, evaluation and anti-inflammatory activity of topical etoricoxib gel", Asian J. Pharm. Clin. Res., 3, 126-129 (2010).

40- I. B. Pathan, C. Mallikarjuna Setty and V. R. M. Gupta, "Comparison of the effect of essential oils on the permeation of diclofenac diethylamine through various barriers", Acta Pharma. Sci., 50, 219-228 (2008).

41- J. R. Kunta, V. R. Goskonda, H. O. Brotherton, M. A. Khan and I. K. Reddy, "Effect of menthol and related terpenes on the percutaneous absorption of propranolol across excised hairless mouse skin", J. Pharm. Sci., 86, 1369-1373 (1997).

42- B. Sapra, S. Jain and A. K. Tiwary, "Percutaneous permeation enhancement by terpenes: Mechanistic view", The AAPS J., 10, 120-132 (2008).

43- V. R. Sinha and M. P. Kaur, "Permeation enhancers for transdermal drug delivery", Drug Dev. Ind. Pharm., 26, 1131-1140 (2000).

44- Y. Kaplun-Frischoff and E. Touitou, "Testosterone skin permeation enhancement by menthol through formation of eutectic with drug and interaction with skin lipids", J. Pharm. Sci., 86, 1394-1399 (1997).

45- T. Ogiso, M. Iwaki and T. Paku, "Effect of various enhancers on transdermal penetration of indomethacin and urea, and relationship between penetration parameters and enhancement factors", $\boldsymbol{J}$. Pharm. Sci., 84, 482-488 (1995).

46- G. L. Xiong, D. Quan and H. I. Maibach, "Effects of penetration enhancers on invitro percutaneous absorption of low molecular weight heparin through human skin", J. Control. Rel., 42, 289-296 (1996).

47- J. Y. Fang, T. H. Tsai, C. F. Hung and W. W. Wong, "Development and evaluation of the essential oil from Magnolia fargesii for enhancing the transdermal absorption of theophylline and cianidanol", $\boldsymbol{J}$.

Pharm. Pharmacol., 56, 1493-1500 (2004).

48- M. K. Das, A. Bhattacharya and S. K. Ghosal, "Effect of different terpenecontaining essential oils on percutaneous absorption of trazodone hydrochloride 
through mouse epidermis", Drug Deliv., 13, 425-431 (2006).

49- M. Saeedi and K. Morteza-Semnani, "Penetration-enhancing effect of the essential oil and methanolic extract of Eryngium bungei on percutaneous absorption of piroxicam through rat skin", J. Essent. Oil Bear. Pl., 12, 728-741 (2009).

50- D. A. Godwin and B. B. Michniak, "Influence of drug lipophilicity on terpenes as transdermal penetration enhancers", Drug Dev. Ind. Pharm., 25, 905-915 (1999).
51. C. M. Setty, Y. Jawarkar and I. B. Pathan, "Effect of essential oils as penetration enhancers on percutaneous penetration of furosemide through human cadaver skin", Acta Pharma. Sci., 52, 159-168 (2010).

52- P. Costa and J. M. Sousa Lobo, "Modeling and comparison of dissolution profiles", Eur. J. Pharm. Sci., 13, 123-133 (2001). 


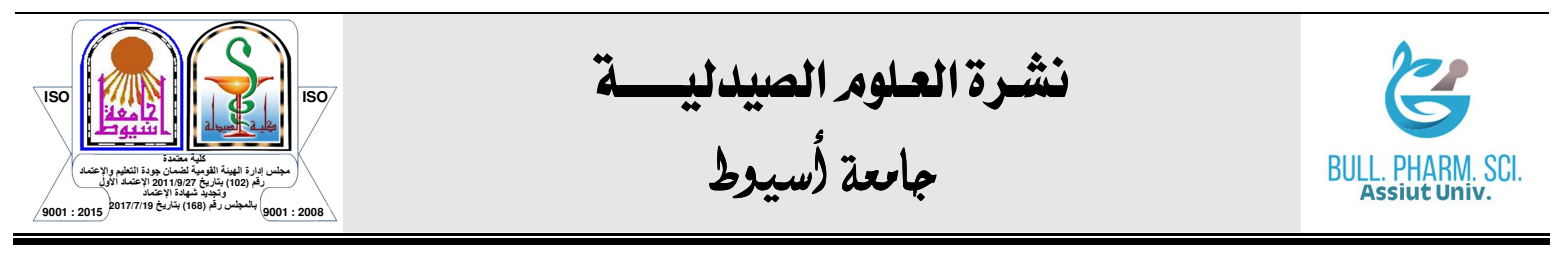

\section{تأثير الزيوت الأساسية على نفاذية سكسينات الميتوبرولول عبر الجلا \\ كيشور كومار سوراثيا - ميهول باتيل - تيجال سوني - فيدور فاجاسيا - باتئ

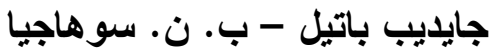

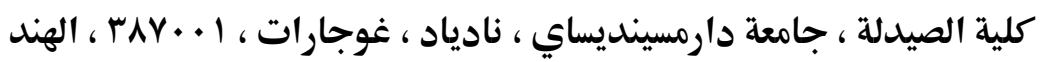

تهدف هذه الدر اسة إلي صياغة سكسينات الميتوبرولول في صورة أنثرطة موضعية كانظمــة

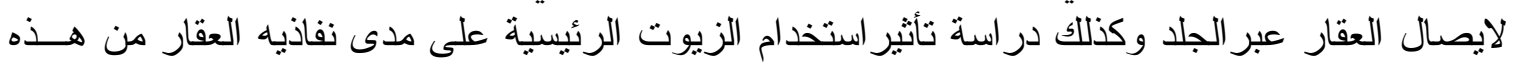

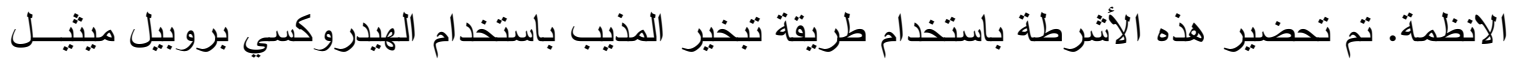

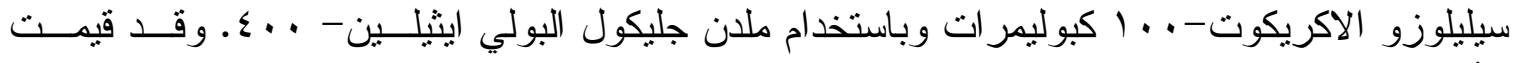

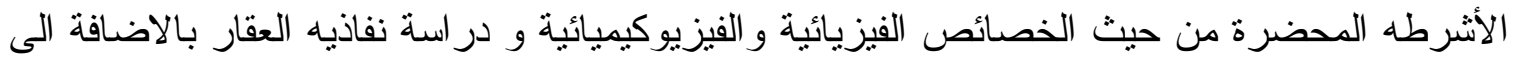

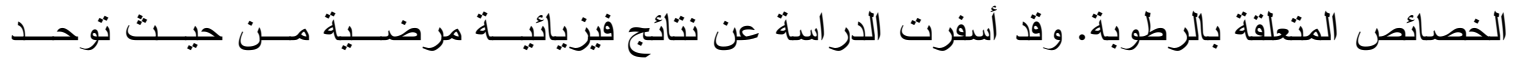

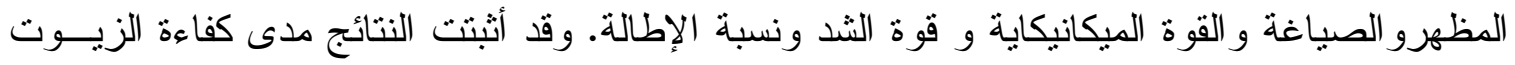

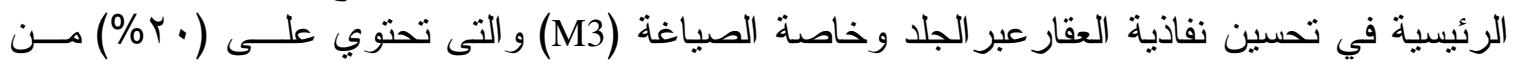

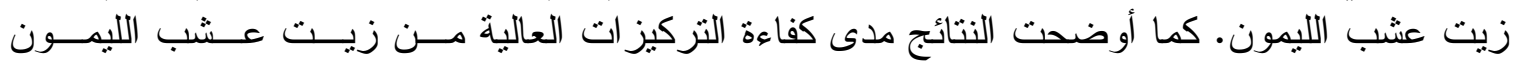

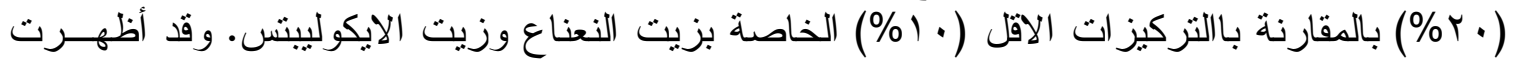

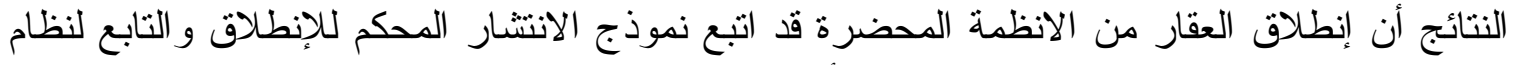

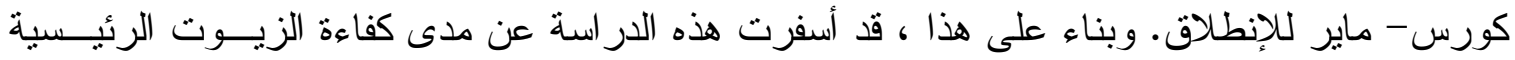
كبديل فعال و آمن لتحسين نفاذية العقاقير المختلفة عبر الجلد. 